\title{
Processing of brewing by-products to give food ingredient streams
}

\author{
Matias Falk Bjerregaard ${ }^{1} \cdot$ Angelos Charalampidis $^{1} \cdot$ Rasmus Frøding $^{1} \cdot$ Radhakrishna Shetty $^{1,5} \cdot$ Helena Pastell $^{3}$. \\ Charlotte Jacobsen ${ }^{1}\left[\right.$ ] Shiwen Zhuang ${ }^{1} \cdot$ Manuel Pinelo ${ }^{2}$. Preben Bøje Hansen ${ }^{4} \cdot$ Timothy John Hobley $^{1}$ (])
}

Received: 18 September 2018 / Revised: 20 December 2018 / Accepted: 22 December 2018

(c) Springer-Verlag GmbH Germany, part of Springer Nature 2019

\begin{abstract}
Very large amounts of brewer's spent grains (BSG) are produced in the world which is usually considered as a waste, or animal feed, rather than food for humans. Here, we report, for the first time, a new process at pilot scale for the separation of brewer's spent grain and trub to solid and liquid streams that can be used in foods. A new type of continuous rotary drum press was used to process hot BSG to produce a liquid filtrate and a filter cake stream. Analysis showed that of the starting mass of BSG (ca. $120 \mathrm{~kg}$ ), the liquid filtrate composed $50 \%$ of the mass, and the filter cake fraction composed $50 \%$ of the mass. The dry weight (DW) content of the BSG increased from 23 to over $35 \%$. This led to concentration of insoluble dietary fibre (from 38 to 54\%) and phenolics in the filter cake (from 102 to $150 \mathrm{mg} / 100 \mathrm{~g} \mathrm{DW}$ as gallic acid equivalents). No fractionation of soluble species such as proteins occurred. Centrifugation of the filtrate from the rotary drum press led to a clarified supernatant stream and a paste. Concentration of insoluble dietary fibre and phenolics occurred in the paste (from 5 to $14 \%$ of DW and 61 to $114 \mathrm{mg} / 100 \mathrm{~g} \mathrm{DW}$ as gallic acid equivalents), whereas soluble fibre and protein did not selectively partition. Given that the unit operations used here are scaleable and approved for food production, an industrially feasible route now exists to process brewers spent grains to ingredients.
\end{abstract}

Keywords Brewer's spent grains $\cdot$ Filter press $\cdot$ Pilot scale $\cdot$ Trub $\cdot$ Separation

\section{Introduction}

During beer production, four main separate streams are generated: wort which is fermented to beer, brewer's spent grains (BSG), denatured protein precipitate after boiling

Electronic supplementary material The online version of this article (https://doi.org/10.1007/s00217-018-03224-6) contains supplementary material, which is available to authorized users.

Timothy John Hobley

tjho@food.dtu.dk

Charlotte Jacobsen

chja@food.dtu.dk

1 National Institute for Food, Technical University Denmark, 2800 Kongens Lyngby, Denmark

2 Department of Chemical Engineering, Technical University Denmark, 2800 Kongens Lyngby, Denmark

3 Finnish Food Safety Authority Evira, Chemistry and Toxicology Research Unit, 00790 Helsinki, Finland

4 Dacofi ApS, Kongens Lyngby, Denmark

5 Present Address: Carlsberg Research Laboratory, Copenhagen, Denmark (trub), and excess yeast. Beer is the main product and the other streams are often perceived as by-products with little or even negative value [1]. In particular, the authors' discussions with many microbreweries in Denmark show that those in rural areas can often have BSG removed at no cost, whilst those in urban areas must pay for disposal. Some large breweries are, however, able to sell BSG for a low price. Barley malt usually comprises the main ingredient in the mashing process and the total mass of BSG generated per brew varies from 20 to 30 weight- $\%$ of the original total mashing weight, depending on the lautering efficiency. This relatively high waste fraction makes BSG a very abundant (ca. 38.6 million tons per year) and cheap material, suitable for exploitation [1]. Furthermore, for every 100 liters of beer produced, $0.2 \mathrm{~kg}$ of trub and $2.5 \mathrm{~L}$ of excess yeast $[2,3]$ are also produced. Given that approximately over 400 million $\mathrm{hL}$ of beer were produced in the EU in 2016 [4], the corresponding amounts of BSG, yeast, and trub can be estimated to be extremely large.

A logistical issue arises for production companies exceeding 1 million hectolitres of beer annually, as the sheer volume of BSG becomes neither feasible nor viable to transport 
and sell as an agricultural feedstock [5, 6]. Furthermore, BSG is subject to rapid microbial contamination due to the rich availability of nutrients $[7,8]$, which can quickly become a hygienic problem for a brewery. Thus, with such large volumes, a limited shelf life, and a traditional view that it does not constitute a foodstuff, an oversupply of BSG quickly reduces its value, and focus is placed on it as an animal feed, as fertiliser, or waste to landfill. With this in mind, some methods have been advanced to store large quantities of BSG over longer periods of time for livestock feed [8]. BSG has been suggested for a range of other applications such as for using it as a biosorbent for cleaning wastewater of copper(II) [9] or in solid-state fermentation processes to enrich the protein content [10].

A window of opportunity exists at the end of the mashing process, however, where BSG remains hot $\left(>70^{\circ} \mathrm{C}\right)$ and exposure to air has been minimal. In this state, there is little microbial contamination and the BSG can be considered for food use [7]. BSG as a food has received increased attention due to its potential to reduce the environmental impact while potentially easing the economic strain on the brewing companies. Some previous studies have examined the potential for using BSG as a human food additive. However, in most cases, they have examined the composition of BSG and from this drawn conclusions about the potential nutritional value and applications, but they have not satisfactorily addressed the industrial challenges associated with downstream processing of BSG [7, 11].

In this study, we examine, for the first time, a new way of continuously processing brewer's spent grains directly after lautering to give food ingredients. A new type of continuous rotary drum press is used at pilot scale, followed by continuous disc-stack centrifugation. We examine two different filter pore sizes $(100 \mu \mathrm{m}$ and $300 \mu \mathrm{m})$ simultaneously in the press and analyse the fractions produced. We also apply this to the trub produced after wort boiling.

\section{Materials and methods}

\section{Materials}

Barley malt was obtained from Sophus Fuglsang Maltfabrik A/S, Denmark. It was two-row spring, Pilsner malt 8070, production date 10-2016, with the following characteristics as stated by the supplier: degree of utilization, 100\%; European Brewing Convention (EBC) colour, 3.7; dry weight, 81.4\%; protein, $9.7 \%$. Microcrystalline cellulose powder, $20 \mu \mathrm{m}$, immunoglobulin $\mathrm{G}$ from bovine blood were obtained from Sigma-Aldrich, as were other chemicals which were of analytical grade.

\section{Methods}

\section{Production of BSG by mashing}

A $600 \mathrm{~L}$ mashing system constructed in-house, based on patent WO2013024065 was used for all mashing. It works in the same way as the lab-scale device reported by us previously [12] and a schematic is shown in Fig. 1. In brief, it consisted of a $600 \mathrm{~L}$ mashing tank $(1.3 \mathrm{~m}$ high, $0.8 \mathrm{~m}$ diameter) with six cylindrical stainless steel filters (each being $0.3 \times 0.07 \mathrm{~m}$; with a $200 \mu \mathrm{m}$ pore size) at the top and six at the bottom connected by a recirculation loop in which there was a large peristaltic pump (Bredel 50, AxFlow AB, Sverige) and heat exchanger (water heated). During mashing, wort was drawn at a rate of ca. $50 \mathrm{~L} / \mathrm{min}$ through one set of filters by the pump, passed through the heat exchanger to maintain the desired temperature and then back through the other set of filters and into the mashing vessel. When a pressure difference of 2 bar was observed in the loop due to fouling of one set of filters, the circulation direction was reversed, cleaning the filters, but progressively fouling the

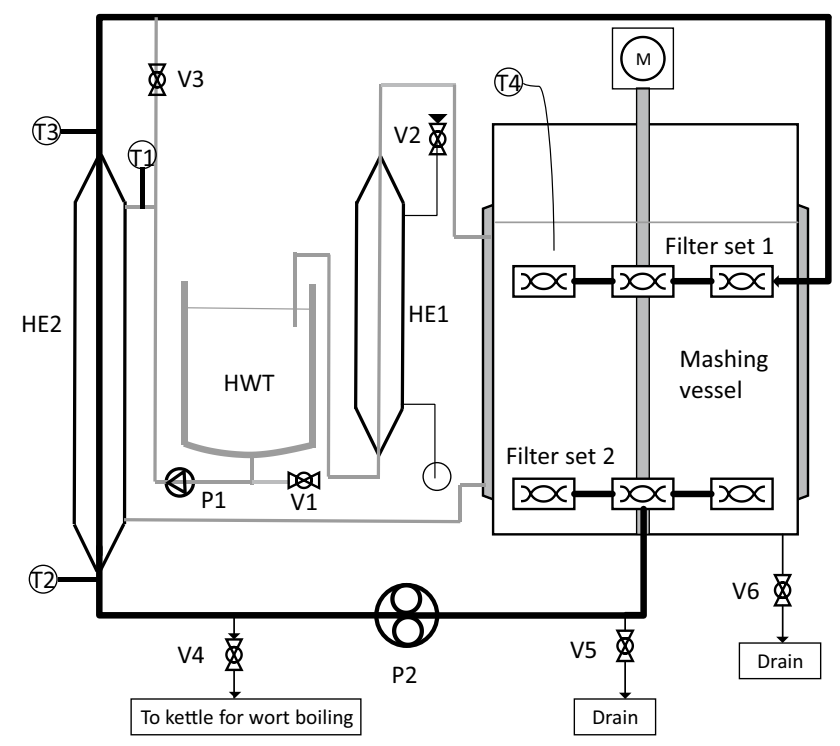

Fig. 1 Schematic of the mashing system used. The hot water tank (HWT) is filled via valve 1 (V1); then, the water is circulated by pump P1 and heated in heat exchanger HE 1 via steam admitted by V2. When, at the correct temperature, the mash kettle is filled with heated water through filter set 1 after opening V3 and malt is added. Mashing commences by closing V3 then drawing wort out of filter set 2 using peristaltic pump P2 and then passing it through HE2 to regulate the temperature and then back into the mashing vessel through filter set 1 . When filter set 2 blocks up with malt particles, the circulation direction is reversed by $\mathrm{P} 2$. When mashing is finished, the wort is pumped out using P2 via V4 to the boiling kettle. Sparge water heated in HWT is added via V3 and filter set 1. T1-T4 are temperature sensors, V1-V6 are valves, and $\mathrm{M}$ is a motor to raise or lower the filter sets 
set now on the intake side. This pattern of flow reversal was repeated (every ca. $5 \mathrm{~min}$ ) until mashing was completed (see Fig. 1).

To start the mashing process, the malt was milled with a Sommer, Piccolo 15 S 400 V (Germany) two roller mill at a setting of 5 (1.25 mm distance between rollers). In a typical process, the mashing vessel was filled with heated tap water (e.g. ca. $450 \mathrm{~L}$ ) and ca. $84.5 \mathrm{~g}$ of citric acid was added to reduce the $\mathrm{pH}$ to 5.8 . When the water was at $56^{\circ} \mathrm{C}$, the required amount of milled malt was added (e.g. $90 \mathrm{~kg}$ ), during which the temperature dropped to ca. $54{ }^{\circ} \mathrm{C}$. Mashing then proceeded with the following temperature profile: $15 \mathrm{~min}$ at $54{ }^{\circ} \mathrm{C}$ where limit dextrinase is active, $60 \mathrm{~min}$ at $65^{\circ} \mathrm{C}$ where beta-amylases mostly are active, and then $5 \mathrm{~min}$ at $72{ }^{\circ} \mathrm{C}$, where the alpha-amylases are most active. Subsequently, the wort was pumped out through the bottom set of filters to the boiling kettle and $150 \mathrm{~L}$ of hot water $\left(72{ }^{\circ} \mathrm{C}\right)$ was used to sparge the spent grains, which was also pumped to the boiling kettle. The total time for draining the wort and then sparging was ca. $15 \mathrm{~min}$. The spent grains were then removed through a man-hole on the side of the mashing vessel, weighed (ca. $120 \mathrm{~kg}$ ), and whilst still hot (ca. $65^{\circ} \mathrm{C}$ ), fed to the rotary drum press.

\section{Processing brewer's spent grains with a rotary drum press}

For these experiments, the hot BSG was manually filled into buckets and then fed into the rotary drum press from the top via an Archimedes-type screw integrated into the central chamber (Fig. 2). The rotary drum press was obtained from Dacofi ApS (Denmark) and consisted of two stainless steel filter drums opposing each other and two rubber coated pressing drums opposing each other. For this work, it was configured with one 100 micron pore size filter drum and simultaneously with a second 300 micron pore size filter drum. The length of each filter and diameter were $0.48 \mathrm{~m}$ and $0.2 \mathrm{~m}$, respectively, giving a total area of each filter of $0.3 \mathrm{~m}^{2}$. These filter and pressing drums were arranged between a top and bottom plate, such that they touched each other forming a water tight central chamber. Thus, the area of each filter actually in contact with the spent grains being added was $0.11 \mathrm{~m}^{2}$. The motor-driven screw traversed the length of the central chamber and observations showed that the BSG filled the space, and was in contact with the whole filter area available. Liquid filtrate from the BSG passed through the filter and was collected from inside by a manifold and peristaltic pump (one for each filter) and the filter surface became fully coated in BSG. The filters and rubber drums all rotated, such that the BSG-fouled filter surface was pressed by the rubber roller releasing more liquid into the filters and leaving a dewatered filter cake that rolled out of the central chamber and was removed with scrapers (Fig. 2) and collected for analysis. Essentially, no BSG adhered to the rubber rollers. The rotational speed of the feeding screw $(30 \mathrm{rpm})$, the filters $(6.8 \mathrm{rpm})$, and rubber drums $(6.8 \mathrm{rpm})$ was the same in all experiments. The peristaltic pumps (Realax RP40, AxFlow AB, Sverige) connected to the manifold from each filter were calibrated to run at the same rate, which, in both cases, was in excess of the filter flux. Samples were stored at $-20^{\circ} \mathrm{C}$ for analysis, except for those used for centrifugation, which were processed directly. An overview of the fractionation process is shown in Fig. 3.

In parallel to processing the BSG, $260 \mathrm{~L}$ of the ca. $500 \mathrm{~L}$ wort was boiled at $100{ }^{\circ} \mathrm{C}$ for $60 \mathrm{~min}$ together with $200 \mathrm{~g}$ of Perle hops pellets and $200 \mathrm{~g}$ of Hallertuer mittelfrüh hops pellets (both from the 2016 harvest and supplied by Caldic Ingredients Denmark A/S) in a hop basket. Perle contained $4.5 \% \alpha$-acids and Hallertuer mittelfrüh 3.5\% $\alpha$-acids. After
Fig. 2 Rotary drum press used to process BSG. Left-hand side: Top schematic view. Right-hand side: picture from side of rotary drum press used in the current work. Legend: a filter drum, b rubber pressing drum, $\mathbf{c}$ liquid passing into filter from central feed chamber for collection, $\mathbf{d}$ scrapers for removing filter cake from filter, and $\mathbf{e}$ feed funnel with Archimedes screw for introducing BSG into central feed chamber
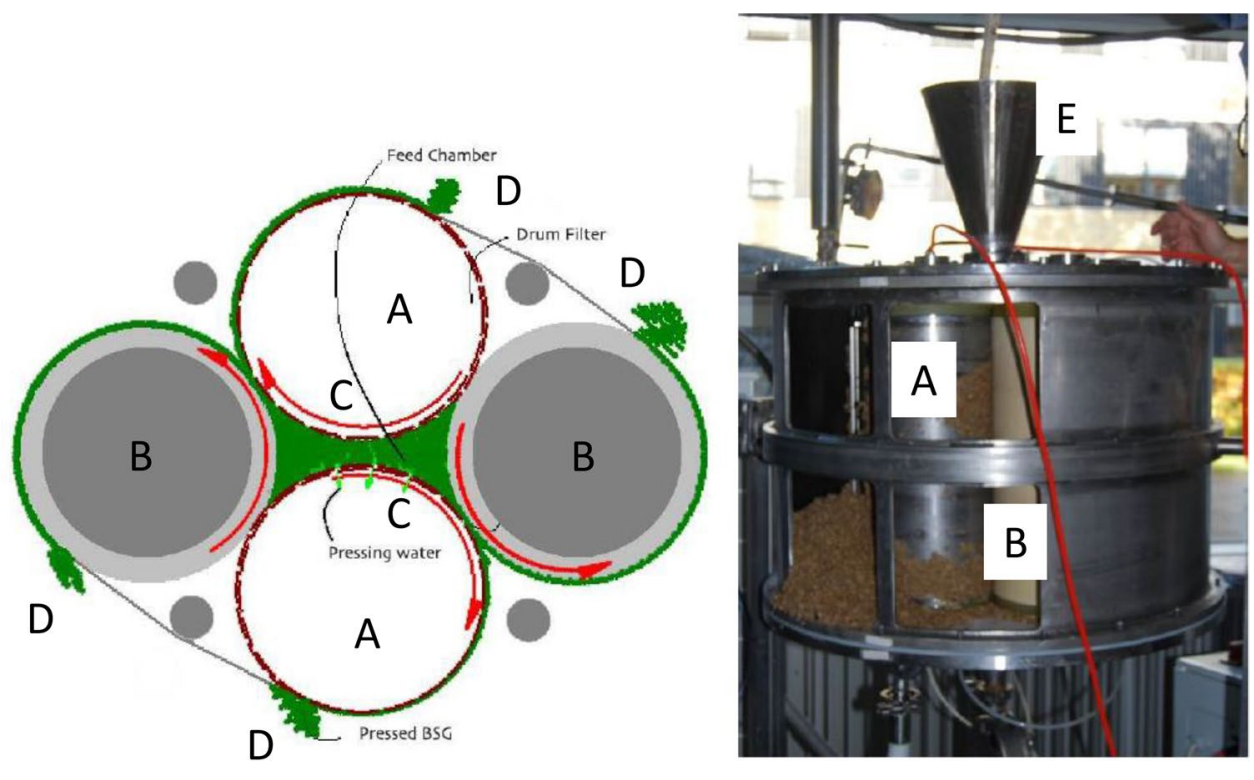
Fig. 3 Overview of the BSG fractionation process investigated. Gray boxes: unit operations used; black boxes: fractions produced and analysed

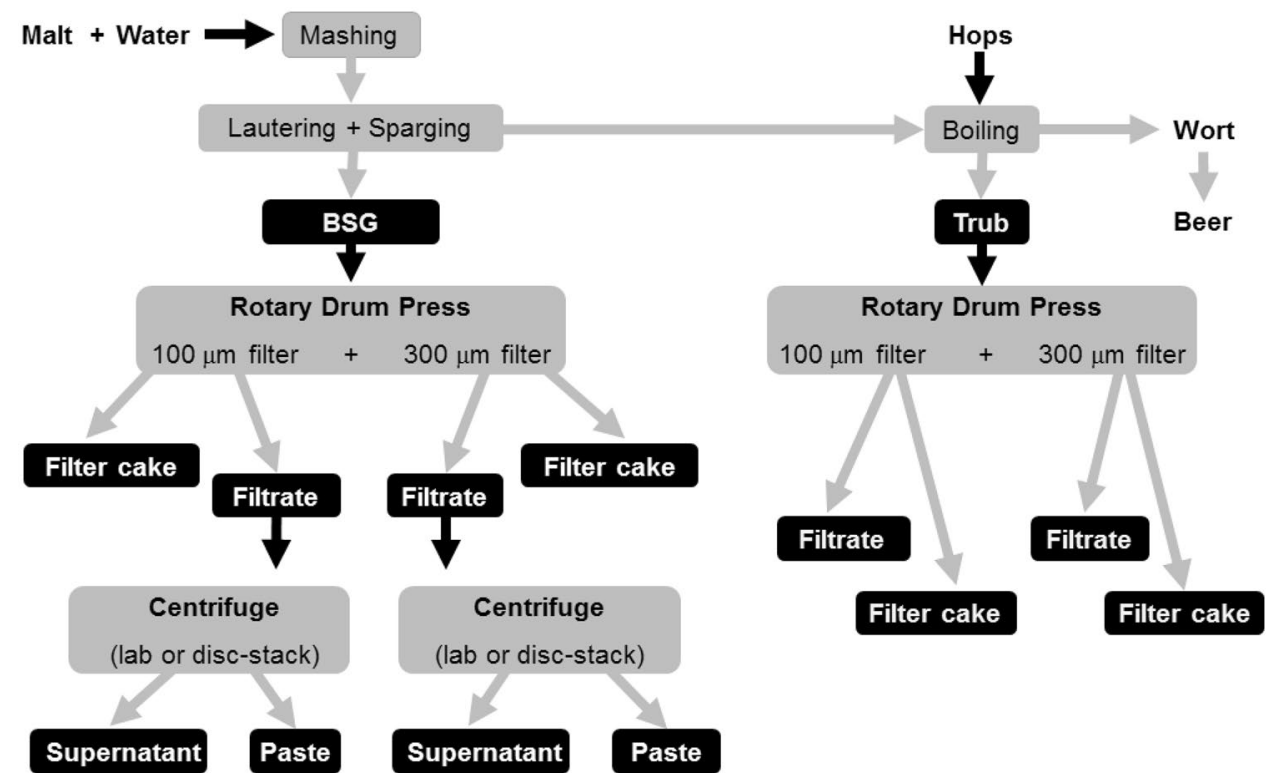

boiling, the wort was transferred to a fermenter, leaving the trub precipitate sludge behind. The trub was then collected and fed into a cleaned rotary drum press in the same way as described for processing BSG (Fig. 3).

\section{Centrifugation of filtrates}

Two types of centrifuge were used to process the filtrates from the rotary drum press (see Fig. 3). The lab centrifuge (Varifuge $20 \mathrm{RS}$, Heraeus Sepatech Group) processed $4 \times 0.5 \mathrm{~L}$ tubes at $4000 \mathrm{rpm}$, equivalent to $3935 \mathrm{~g}$. The discstack centrifuge (SAOH 205, Westfalia Separator AG) was operated continuously to process all of the filtrate from the 100 micron and 300 micron filters. It was operated at $10,000 \mathrm{rpm}$ giving a relative centrifugal force of $17,664 \mathrm{~g}$. A two-phase split of the liquid filtrate could be produced and water jet injection was used to release the particle laden phase. Moreover, when the $300 \mu \mathrm{m}$ filtrate was processed, the two valves controlling the "heavy" and "light" outlet flow rates were adjusted, such that a very thick paste was continuously produced comprising the accumulated dense particles from the filtrate. All samples for analysis were promptly frozen. Observations showed that a significant sedimentation was seen if samples of the filtrate were stored at $4{ }^{\circ} \mathrm{C}$ for a number of days. This suggests that simple decantation may also be a possible clarification method.

\section{Analysis}

\section{Solvent extraction of proteins}

For all solid samples, i.e., malt, BSG, pressed BSG, and the paste from centrifugation, $100 \mathrm{mg}$ (dry weight equivalent) was mixed in a vortex mixer with $3.0 \mathrm{ml}$ of either solvent $\mathrm{A}$ [5.0\% (w/v) $\mathrm{NaCl}], \mathrm{B}$ [55.0\% (v/v) 1-propanol] or C (6 M urea, $\mathrm{pH} \mathrm{8.4)}$ at room temperature (RT) for solvents $\mathrm{A}$ and $\mathrm{C}$ and $60^{\circ} \mathrm{C}$ for solvent $\mathrm{B}$ and then extracted by subsequent shaking for $10 \mathrm{~min}$. The suspensions were centrifuged (1500 g; $10 \mathrm{~min}$; RT) and the supernatant was then diluted to $10 \mathrm{ml}$ with the respective extraction solvent [13]. Solvent A was used to extract the albumin and globulin fraction that is water and salt soluble, solvent B was used to extract the hordein fraction that is alcohol soluble, and solvent $\mathrm{C}$ was used to extract the glutamine fraction, as described by the Osborne method for fractionation [13, 14].

\section{Protein concentration}

Total protein was determined using both the Kjeldahl and Dumas methods to be able to compare the suitability of the two methods for BSG analysis as recently reported by Kupetz et al. [15]. The Kjeldahl assay was used to measure total nitrogen using a method reported in Oehlenschläger [16]. A conversion factor of 6.25 was applied, which is equivalent to $16 \%$ nitrogen content in the protein. The reference protein used was $\operatorname{IgG}$.

The Dumas assay was conducted using an automated technique with a Rapid Max N Excced (Elementar), in which the organic sample was combusted in a small crucible at $900{ }^{\circ} \mathrm{C}$ and the protein content in the sample determined using the accompanying software. Aspartic acid was used to calibrate the instrument. Jones [17], and the rapid MAX N exceed $®$ technical notes [18] suggest that an N/p-factor of 5.83 is most appropriate for barley and other cereals. However, the N/p-factor of 6.25, known as 
the Kjeldahl factor, has been widely adopted by the other workers and was used in the current work.

The Bradford assay was used to measure soluble protein and the Coomassie plus reagent (Thermo Scientific) was used according to the manufacturer's instructions. The colour was measured after $10 \mathrm{~min}$ incubation at room temperature using a Shimadzu UV-1201 VIS spectrophotometer at $595 \mathrm{~nm}$. IgG was used as standard.

The Amido black assay was used when sample size was limited (i.e., from the Osborne fractionation method) and prior to trypsin digestion for mass spectrometry. This was performed as reported by Popov et al. [19], with minor modifications for smaller volumes. The amido black 10B dye (Sigma-Aldrich) was dissolved in a washing solution of $90 \%$ methanol and $10 \%$ acetic acid to give $0.26 \mathrm{~g} / \mathrm{L}$, left to stand at room temperature for $4 \mathrm{~h}$, and then, filtered to give the staining solution. Liquid, extracted or enzyme hydrolysed samples $(50 \mu \mathrm{g})$ were mixed with $300 \mu \mathrm{l}$ of stain solution for $5 \mathrm{~min}$ in a $2 \mathrm{ml}$ 'Eppendorf' centrifuge tube. The mixture was then centrifuged for $5 \mathrm{~min}$ at $14,000 \mathrm{rpm}$ in a bench top 'Eppendorf' centrifuge. The supernatant was discarded and $500 \mu \mathrm{l}$ of washing solution (90\% methanol and $10 \%$ acetic acid) added. The new mixture was centrifuged and the supernatant was discarded, and the step was repeated until the supernatant became colourless (two washes). The pellet was subsequently dissolved in $250 \mu \mathrm{l}$ of $0.1 \mathrm{~N} \mathrm{NaOH}$ and the adsorbance measured at $615 \mathrm{~nm}$. A standard curve with BSA was used as reference.

\section{Liquid chromatography-mass spectrometry (LC-MS) for protein identification}

All samples were precipitated and digested with trypsin before analysis using the method reported in Glatter et al. [20]. In brief, the precipitate was dissolved in $8 \mathrm{M}$ Urea, $50 \mathrm{mM}$ Tris- $\mathrm{HCl} \mathrm{pH} 8.0$ with $41 \mathrm{mM}$ DTT and incubated for $45 \mathrm{~min}$ at room temperature. Sufficient iodoacetamide was then added to give a concentration of $91 \mathrm{mM}$ and the sample incubated for $1 \mathrm{~h}$ before starting digestion overnight with a protein:trypsin ratio of 50:1. After incubating overnight at $25{ }^{\circ} \mathrm{C}$ the reaction was stopped by adding $10 \%$ TFA to give a concentration of ca. $0.4 \%$ TFA. Subsequently, they were analysed with an EASYnLC II 1000 nanoflow liquid chromatograph coupled to a Q Exactive ${ }^{\mathrm{TM}}$ Hybrid Quadrupole-Orbitrap ${ }^{\mathrm{TM}}$ Mass Spectrometer, both of them from Thermo Fisher Scientific. The results from the mass spectrum were compared to data retrieved for barley from the Uniprot database. The proteins were identified using MaxQuant proteomics software.

\section{Total phenolic content (TPC)}

The method was performed as described earlier [21, 22], giving a value for the total content of phenolic compounds in gallic acid equivalents (GAE) on a dry weight (DW) basis. In brief, a $100 \mu \mathrm{l}$ sample was mixed with $0.75 \mathrm{ml}$ of a 1:10 diluted Folin-Ciocalteu reagent and incubated at room temperature for $5 \mathrm{~min}$. Sodium carbonate $(0.75 \mathrm{ml}$ of a $6 \%$ solution) or sodium bicarbonate (there was no difference in using either, data not shown) was added to the mixture and further incubated at room temperature for $90 \mathrm{~min}$ before measuring the adsorbance at $725 \mathrm{~nm}$ and comparing to a calibration curve made using a solution of gallic acid. For solid samples, an extraction was performed using methanol, rather than water or ethanol, as advanced by the previous workers [20]. Methanol $(5 \mathrm{ml})$ was added to $0.2 \mathrm{~g}$ of solid sample and sonicated for $30 \mathrm{~min}$ then centrifuged at $3500 \mathrm{rpm}$ for $10 \mathrm{~min}$, and the supernatant collected. The supernatant was subsequently evaporated by continuous nitrogen flow. The extraction process was repeated twice, and the final dry sample sediment was weighed. This sediment was redissolved in $5 \mathrm{ml}$ methanol and a $100 \mu \mathrm{l}$ aliquot was then subjected to similar processing as the liquid samples.

\section{Iron $\left(\mathrm{Fe}^{2+}\right)$ chelating antioxidant activity}

The method advanced by Farvin et al. [23] was employed. In brief, $110 \mu \mathrm{L}$ of the extract (at a concentration range of $1-2000 \mu \mathrm{g} / \mathrm{ml}$ ) was transferred to a microtiter plate, where $110 \mu \mathrm{L}$ of deionised water and $20 \mu \mathrm{L}$ of $2 \mathrm{mM}$ ferrous chloride were added. After $3 \mathrm{~min}, 20 \mu \mathrm{L}$ of $5 \mathrm{mM}$ ferrozine was added, the mixture shaken and then incubated at room temperature for $10 \mathrm{~min}$. The absorbance was then measured at $562 \mathrm{~nm}$ using a spectrophotometer (Shimadzu UV 1201 UV-VIS). A blank was made using distilled water instead of sample. EDTA at a concentration of $200 \mu \mathrm{g} / \mathrm{ml}$ was used as reference. Controls were made for each extract without adding ferrozine.

\section{DPPH radical scavenging antioxidant activity}

The method of Farvin et al. [22] was used, in which 1,1-diphenyl-2-picrylhydrazyl (DPPH) solution (100 $\mu \mathrm{L}$, $0.1 \mathrm{mM}$ in $96 \%$ ethanol) was mixed with $100 \mu \mathrm{L}$ of extract made in the same way as for total phenolics determination (at a concentration range of $1-2000 \mu \mathrm{g} / \mathrm{ml}$ ). The mixture was shaken and left for $30 \mathrm{~min}$ at room temperature. The absorbance of the resulting solution was measured at $517 \mathrm{~nm}$ using a spectrophotometer. For the blank, distilled water was used instead of the sample and a sample control was also made for each fraction by mixing $100 \mu \mathrm{L}$ of sample with $100 \mu \mathrm{L}$ of $96 \%$ ethanol. A reference with butylated hydroxytoluene (BHT) at a concentration of $200 \mu \mathrm{g} / \mathrm{ml}$ was also made in 
a similar manner. Radical scavenging activity for the individual concentrations tested the capacity expressed as the concentration of extract required to scavenge $50 \%$ of DPPH radicals (EC50) which were calculated as reported in Farvin et al. [22].

\section{Soluble sugars}

A GlycoChrom Analyzer with refractive index detector was used, running a mobile phase of $5 \mathrm{mM}$ sulfuric acid at $0.6 \mathrm{~mL} / \mathrm{min}$ on an Animex HPX-87H column $(300 \times 7.8 \mathrm{~mm})$, at $60{ }^{\circ} \mathrm{C}$. Peak areas were determined and related to standard curves made with pure sugars.

\section{Dietary fibre}

Samples were freeze-dried before transporting to Finland for analysis, which was performed using the AOAC Method 2011.25 and the Megazyme total dietary fibre assay kit (Megazyme, Ireland) according to the manufacturer's instructions. Upon arrival, the samples were ground and starch, and protein in them was degraded using $\alpha$-amylase, amyloglucosidase, and protease. The samples were then filtered twice through a crucible filter (coarse, ASTM 40-60 $\mu \mathrm{m})$. The insoluble dietary fibre (IDF) was collected as residue and all soluble fibres were located in the filtrate. Ethanol was added to the filtrate causing precipitation of the water-soluble polysaccharides (SDFP) which were collected on a filter crucible. The second filtrate containing only the oligosaccharides (SDFS) was desalted and analysed by HPLC using Sugar-Pak ${ }^{\circledR}$ column $(6.5 \times 300 \mathrm{~mm}$; Waters Corporation, Milford, MA, USA). The two residues, IDF and SDFP, were dried and weighed, and their ash and residual protein contents were analysed using a muffle furnace $\left(550{ }^{\circ} \mathrm{C}, 3 \mathrm{~h}\right)$ and a Kjeldahl Auto Sampler Analyzer Unit (FOSS, Kjeltec 8400, Hillerød, Denmark), respectively. Thus, each fibre content could be calculated by subtracting the residual protein and ash content from the total mass. The total dietary fibre amount in the samples was determined as $\mathrm{IDF}+\mathrm{SDFP}+$ SDFS

\section{Particle-size distribution}

The particle distribution of both liquid streams and their centrifugation products were determined using a Malvern ${ }^{\circledR}$ Mastersizer 2000 particle analyser APA2000 with Hydro 2000G sample dispersion accessory filled with distilled water. The refractive index of cellulose (1.46) was used and a $20 \mu \mathrm{m}$ microcrystalline cellulose powder from SigmaAldrich was used as a gross check. Results are expressed as volume percent.

\section{Free amino nitrogen (FAN)}

The FAN analysis was performed as described in Analytica-EBC by the European Brewery Convention (EBC 9.10.1), with slight modifications as described below. Liquid samples were centrifuged to remove particles and were diluted 1:100, before being analysed. Glycine standards were used.

\section{Viscosity}

A StressTech rheometer (Rheologica Instruments AB, Lund, Sverige) with a $4^{\circ}$ cone plate (C40) was used or, for the solid containing paste, a coaxial cylinder piston (CC25) was used. A shear rate interval of 1-777.2 $\mathrm{S}^{-1}$ was chosen and the StressTech software was used to determine viscosity as a function of shear rate.

\section{Other analyses}

Specific gravity was measured by weighing precisely $100 \mathrm{ml}$ of liquid in a volumetric flask at $20^{\circ} \mathrm{C}$.

The dry matter fraction or dry weight (DW) was obtained via drying to constant weight at $100{ }^{\circ} \mathrm{C}$. No human or animal trials were conducted in this study.

\section{Results}

\section{Fractionation of BSG}

Hot BSG (ca. $65^{\circ} \mathrm{C}$ ) was taken directly from the mashing process following sparging and lautering and pressed with the rotary drum press. Two streams were produced simultaneously, from each of the 100 micron and 300 micron filters, namely a dewatered solid (i.e. a filter cake) and a liquid filtrate stream. The flux of the filtrate from each filter was measured during operation and found to be constant over the time measured, and the result for the 100 micron filter is shown in Fig. 4. The calculated rate of liquid permeate was $134 \mathrm{~kg} / \mathrm{h}(129 \mathrm{~L} / \mathrm{h})$ from each filter and the $120 \mathrm{~kg}$ of BSG was processed within the $560 \mathrm{~s}$ shown in Fig. 4. Given that the surface area of the filter exposed to the spent grains is $0.1096 \mathrm{~m}^{2}$, then the flux of each filter can be calculated to be $1181 \mathrm{~L} / \mathrm{m}^{2} / \mathrm{h}$. The composition of the filtrate from the 300 micron filter was compared at the start of processing, in the middle, and at the end of processing. Small increases in total nitrogen, FAN, soluble protein, glucose and maltose, and specific gravity were seen (Table 1), most likely due to the classification of the BSG during mashing and lautering in the brewing process. 


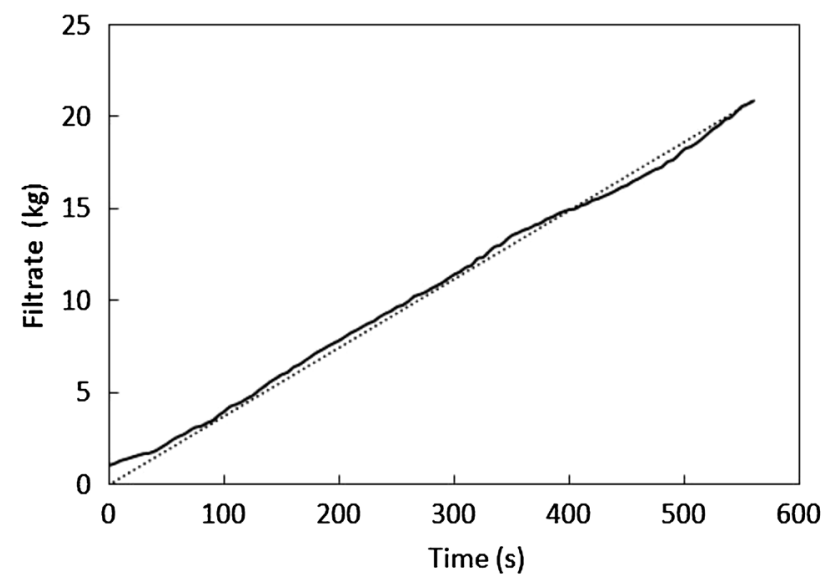

Fig. 4 Filtration rate from the 100 micron filter immediately after starting and for a $560 \mathrm{~s}$ period during which all of the $120 \mathrm{~kg}$ of BSG available was processed. The rate of filtrate produced as found by fitting a straight line to the data is $0.0373 \mathrm{~kg} / \mathrm{s}$

Therefore, in the further work, samples for analysis were taken from the complete pool of the relevant fraction after all BSG had been processed.

Six separate batches of BSG of between 104 and $120 \mathrm{~kg}$ were processed, each made from an identical mashing process with the same pilsner malt batch, and similar results were obtained for each. A complete summary from one of the batches is presented in Table 2. Here, it can be seen that fractionation of some components in the BSG occurred. Processing by the rotary drum press led to close to $50 \%$ of the initial BSG mass ending in a liquid filtrate stream and $50 \%$ as a filter cake stream from either the 100 or the 300 micron filter (Table 2, see also Fig. 3). Consequently, the filter cake produced had the dry matter content increased from ca. $23 \%$ in the BSG to over $35 \%$ from either of the filters. In preliminary experiments, increasing the pressure between the filters and rubber rollers was found to be able to increase the dry matter content in the filter cake to $42 \%$, but at the risk of denting the filter types used in the current work. As may be expected, the 100 micron filter was better at excluding solids, as shown by the composition of the filtrate collected from it which contained $8.9 \%$ of the solids. In contrast, that from the 300 micron filter contained $13.42 \%$ of the solids (Table 2).

Fractionation of antioxidants and some fibre types was also possible by the rotary drum press. Up-concentration of total phenolics was seen in the filter cake from both filters, increasing from ca. $100 \mathrm{mg} \mathrm{GAE} / 100 \mathrm{~g} \mathrm{DW}$ in the BSG to ca. $150 \mathrm{mg} \mathrm{GAE} / 100 \mathrm{~g}$ DW in the filter cake. Consequently the total phenolics decreased in the liquid fractions. EC50 for DPPH was lower in the filtrate $(1 \mathrm{mg} / \mathrm{L})$ than the filter cake $(2500 \mathrm{mg} / \mathrm{L})$, i.e., there was a higher antioxidant activity in the filtrate. For the antioxidant activity shown by iron chelation, there was no change in the fractions compared to the BSG (20\% versus $20.6 \%$ ). Furthermore, an up-concentration of IDF fibre was seen in the filter cake, rising from ca. $38 \%$ of DW to ca. $50 \%$, and decreasing drastically to between 5 and $9 \%$ of DW in the liquid fractions (Table 2). This is consistent with the increase in dry matter content and phenolics in the filter cake. A slight up-concentration of SDFS fibre was seen in the filtrate from both filters compared to the starting BSG and the filter cake. For SDFP fibre and total nitrogen measured by the Kjeldahl or Dumas, no preferential fractionation was seen to the filtrate or filter cake streams. For soluble protein and soluble sugars, similar concentrations were seen in both liquid fractions (Table 2). The Kjeldahl and Dumas methods gave results which were not statistically different and it was concluded that the much more rapid Dumas method can substitute the Kjeldahl in future work, which is in agreement with the recent findings of Kupetz et al. [15]. The overall mass balance for the BSG batch processed in Table 2 was found to close within $0.5 \%$ and for the other BSG batches, it closed within $4 \%$.

\section{Fractionation of filtrate streams using laboratory and continuous disc-stack centrifugation}

Pressing of the BSG with the rotary drum press gave a liquid filtrate stream from each of the 100 and 300 micron filters, which accounted for approximately $50 \%$ of the starting BSG mass. These filtrate streams were essentially opaque and contained soluble and insoluble substances. For some applications, such as in drinks, it would be beneficial to have clarified liquids. Centrifugation is easily

Table 1 Composition of the 300 micron filtrate at the start, middle, and end of processing $102 \mathrm{~kg}$ of BSG

\begin{tabular}{lllllll}
\hline Sample & $\begin{array}{l}\text { Total nitrogen } \\
(\% \text { of } \mathrm{DW})^{\mathrm{a}}\end{array}$ & FAN $(\mathrm{mg} / \mathrm{L})$ & Soluble protein $(\mathrm{g} / \mathrm{L})$ & Maltose $(\mathrm{g} / \mathrm{L})$ & Glucose $(\mathrm{g} / \mathrm{L})$ & Specific gravity $(\mathrm{L} / \mathrm{kg})$ \\
\hline Start & 0.283 & 84 & 0.199 & 27.47 & 6.48 & 1.029 \\
Middle & 0.324 & 109 & 0.185 & 33.42 & 7.62 & 1.0364 \\
End & 0.334 & 117 & 0.197 & 39.67 & 9.34 & 1.0404 \\
Average \pm std dev & $0.314 \pm 0.027$ & $104 \pm 17$ & $0.194 \pm 008$ & $33.5 \pm 6.1$ & $7.82 \pm 1.44$ & $1.0353 \pm 0.006$ \\
\hline
\end{tabular}

a Dumas method used 
Table 2 Composition of fractions produced following processing of BSG or trub with a rotary drum press

\begin{tabular}{|c|c|c|c|c|c|c|c|c|}
\hline \multicolumn{3}{|c|}{ Properties measured after filtration } & \multirow[t]{2}{*}{ Wort } & \multirow{2}{*}{$\begin{array}{l}\text { By-product } \\
\text { (BSG or } \\
\text { trub) }\end{array}$} & \multicolumn{2}{|c|}{ Liquid fraction, filtrate } & \multicolumn{2}{|c|}{ Solid fraction, filter cake } \\
\hline & & & & & $100 \mu \mathrm{m}$ & $300 \mu \mathrm{m}$ & $100 \mu \mathrm{m}$ & $300 \mu \mathrm{m}$ \\
\hline \multirow[t]{16}{*}{ Pilsner BSG } & \multirow[t]{2}{*}{ Wet matter } & Wet mass $(\mathrm{kg})$ & 504.77 & 120.23 & 25.39 & 35.05 & 23.91 & 35.3 \\
\hline & & $\begin{array}{l}\text { Percentage of wet } \\
\text { mass ending in } \\
\text { this fraction }\end{array}$ & $\mathrm{Na}$ & $\mathrm{Na}$ & 21.22 & 29.29 & 19.98 & 29.50 \\
\hline & \multirow[t]{3}{*}{ Dry matter } & Dry mass (kg) & 57.43 & 27.74 & 2.40 & 3.62 & 8.58 & 12.36 \\
\hline & & Dry weight- $\%^{a}$ & 11.38 & 23.08 & 9.45 & 10.33 & 35.9 & 35.03 \\
\hline & & $\begin{array}{l}\text { Percentage of dry } \\
\text { mass ending in } \\
\text { this fraction }\end{array}$ & $\mathrm{Na}$ & $\mathrm{Na}$ & 8.90 & 13.42 & 31.81 & 45.87 \\
\hline & \multirow{2}{*}{$\begin{array}{l}\text { Total Protein (\% of } \\
\text { the dry weight) }\end{array}$} & Kjeldahl $^{\mathrm{b}}$ & 4.71 & 16.34 & 15.78 & 18.98 & 17.04 & 16.56 \\
\hline & & Dumas & 3.82 & 20.78 & 15.25 & 20.96 & 18.97 & 16.84 \\
\hline & \multicolumn{2}{|c|}{$\begin{array}{l}\text { Soluble protein }(\mathrm{mg} / \mathrm{ml} \text {; BSA equivalent } \\
\text { by Bradford })^{\mathrm{c}}\end{array}$} & $0.300 \pm 0.016$ & $\mathrm{Na}$ & $0.262 \pm 0.007$ & $0.261 \pm 0.028$ & $\mathrm{Na}$ & $\mathrm{Na}$ \\
\hline & Antioxidants & $\begin{array}{l}\text { Total phenolics } \\
\text { (mg/100 g) as } \\
\text { GAE on a dry wt } \\
\text { basis }^{\mathrm{d}}\end{array}$ & 113 & 102 & 61 & 75 & 148 & 151 \\
\hline & \multirow{2}{*}{$\begin{array}{l}\text { Soluble sugars } \\
(\mathrm{g} / \mathrm{L})\end{array}$} & Maltose $^{c}$ & $\mathrm{Na}$ & $\mathrm{Na}$ & $31.52 \pm 0.52$ & $36.44 \pm 0.65$ & $\mathrm{Na}$ & $\mathrm{Na}$ \\
\hline & & Glucose $^{c}$ & $\mathrm{Na}$ & $\mathrm{Na}$ & $5.33 \pm 0.37$ & $6.04 \pm 0.25$ & $\mathrm{Na}$ & $\mathrm{Na}$ \\
\hline & \multirow{4}{*}{$\begin{array}{l}\text { Dietary fibre }(\% \text { of } \\
\text { DW) }\end{array}$} & $\mathrm{IDF}^{\mathrm{e}}$ & 0 & 38.38 & 5.05 & 9.03 & 53.83 & 46.48 \\
\hline & & $\mathrm{SDFP}^{\mathrm{e}}$ & 1.49 & 1.77 & 2.32 & 1.81 & 2.50 & 1.32 \\
\hline & & $\mathrm{SDFS}^{\mathrm{e}}$ & 5.92 & 2.20 & 3.82 & 3.49 & 1.02 & 0.99 \\
\hline & & Total $\mathrm{DF}^{\mathrm{e}}$ & 7.32 & 42.35 & 11.18 & 14.33 & 57.35 & 48.79 \\
\hline & \multicolumn{2}{|l|}{$\operatorname{Ash}(k g)^{f}$} & 0.675 & 0.741 & 0.0294 & 0.0449 & 0.3044 & 0.4597 \\
\hline \multirow[t]{3}{*}{ Trub } & \multicolumn{2}{|l|}{ Wet mass (kg) } & $\mathrm{Na}$ & 27.31 & 16.25 & 7.36 & 0.61 & 1.52 \\
\hline & \multicolumn{2}{|l|}{$\%$ Dry weight ${ }^{\mathrm{a}}$} & $\mathrm{Na}$ & $\mathrm{Na}$ & 13.7 & 13.7 & 26.6 & 27.1 \\
\hline & \multicolumn{2}{|c|}{$\begin{array}{l}\text { Total protein by Dumas ( } \% \text { of the dry } \\
\text { weight })^{g}\end{array}$} & $\mathrm{Na}$ & $\mathrm{Na}$ & $0.60 \pm 0.052$ & $0.61 \pm 0.064$ & $6.51 \pm 0.074$ & $6.69 \pm 0.288$ \\
\hline
\end{tabular}

$N d$ not detected, $N a$ not applicable, $I D F$ insoluble dietary fibre, SDFP soluble in water, but precipitates in ethanol, SDFS soluble in water, not precipitated in ethanol (oligosaccharides), Total DF total dietary fibre, GAE gallic acid equivalents

The results are representative of five separate experiments (two for trub). The data from all can be found in supplementary data

${ }^{a}$ Average of duplicate samples (values differed from the average by $<8 \%$ )

${ }^{b}$ Values are averages of one sample analysed in duplicate (values differed from the average by $<5 \%$ )

${ }^{\mathrm{c}}$ Average and standard deviation of quadruplicate analysis

${ }^{\mathrm{d}}$ Averages of two samples (values differed from the average by $<12 \%$ )

${ }^{\mathrm{e}}$ Averages of two samples (values differed from the average by $<5 \%$ )

${ }^{\mathrm{f}}$ Averages of two samples, (values differed from the average by $<11 \%$ )

${ }^{\mathrm{g}}$ Average and standard deviation of triplicate analysis

scaleable and it was, therefore, investigated as a means of further fractionating the filtrates. First, a large laboratory centrifuge was employed, capable of centrifuging ca. $500 \mathrm{~mL}$ of filtrate in each bucket. The trials were done in duplicate for two of the BSG batches treated by the rotary drum press and the results were then scaled for the total amount of each filtrate. The results for both batches were similar and those corresponding directly to the results presented in Table 2 are shown in Table 3. Two trials were also conducted (with all the filtrate from two separate batches of rotary drum press processed BSG) with a small continuous disc-stack centrifuge to confirm that the filtrates can be processed continuously in this way, and the results from one of those are also found in Table 3. The results confirm that the filtrates contained large amounts of particles, rather than colloids only. The 300 micron filter did contain more solids than that from the 100 micron filter, leading to ca. one-third of the volume ending as a thick paste-like pellet, which contained two-thirds of the mass from that filtrate. In contrast the 
Table 3 Composition of fractions after centrifugation of filtrates from two similar sets of pressed BSG

\begin{tabular}{|c|c|c|c|c|c|c|c|c|}
\hline \multicolumn{3}{|c|}{ Properties measured after centrifugation } & \multicolumn{3}{|c|}{$100 \mu \mathrm{m}$ filtrate } & \multicolumn{3}{|c|}{$300 \mu \mathrm{m}$ filtrate } \\
\hline & & & $\begin{array}{l}\text { Filtrate from } \\
\text { filter }\end{array}$ & Supernatant & Paste & $\begin{array}{l}\text { Filtrate from } \\
\text { filter }\end{array}$ & Supernatant & Paste \\
\hline \multirow[t]{15}{*}{ Lab centrifuge } & \multirow[t]{2}{*}{ Wet matter } & Wet mass (kg) & 25.39 & 18.62 & 6.77 & 35.05 & 22.31 & 12.74 \\
\hline & & $\begin{array}{l}\% \text { Of wet mass } \\
\text { in this frac- } \\
\text { tion }\end{array}$ & $20.85 \pm 0.65$ & 73.34 & 26.66 & $27.08 \pm 2.44$ & 63.65 & 36.35 \\
\hline & \multirow[t]{3}{*}{ Dry matter } & Dry mass $(\mathrm{kg})^{\mathrm{a}}$ & 2.4 & 1.32 & 1.18 & 3.62 & 1.67 & 2.36 \\
\hline & & Dry weight- $\%^{\mathrm{b}}$ & 8.09 & 7.10 & 17.46 & 8.67 & 7.51 & 18.5 \\
\hline & & $\begin{array}{l}\% \text { Of dry mass } \\
\text { in this frac- } \\
\text { tion }\end{array}$ & $8.37 \pm 0.5$ & $20.35 \pm 0.19$ & $18.28 \pm 0.19$ & $12.06 \pm 1.19$ & $23.59 \pm 2.81$ & $37.78 \pm 2.32$ \\
\hline & \multirow{2}{*}{$\begin{array}{c}\text { Total protein, } \% \\
\text { of dry weight }\end{array}$} & Kjeldahl $^{\mathrm{b}}$ & 16.49 & 4.53 & 32.19 & 18.21 & 4.61 & 32.53 \\
\hline & & Dumas & 15.25 & 3.63 & 32.55 & 20.96 & $\mathrm{Nd}$ & 34.20 \\
\hline & \multicolumn{2}{|c|}{$\begin{array}{l}\text { Soluble protein }(\mathrm{mg} / \mathrm{ml} ; \mathrm{BSA} \\
{\text { equivalent })^{\mathrm{b}}}^{\text {(n) }}\end{array}$} & 0.262 & 0.173 & 0.293 & 0.261 & 0.210 & 0.232 \\
\hline & Antioxidants & $\begin{array}{l}\text { Total phenolics } \\
\text { (mg GAE } \\
\text { /100 g) on } \\
\text { DW basis }\end{array}$ & 61.34 & 63.06 & 114.63 & 75.5 & 76.26 & 114.0 \\
\hline & \multirow{4}{*}{$\begin{array}{l}\text { Dietary fibre (\% } \\
\text { of DW) }\end{array}$} & $\mathrm{IDF}^{\mathrm{d}}$ & 5.05 & 0.00 & 14.42 & 9.03 & 0.00 & 16.80 \\
\hline & & SDFP $^{d}$ & 2.32 & 2.09 & 0.70 & 1.81 & 1.67 & 1.61 \\
\hline & & SDFS $^{\mathrm{d}}$ & 3.82 & 5.23 & 4.49 & 3.49 & 4.73 & 4.81 \\
\hline & & Total $\mathrm{DF}^{\mathrm{d}}$ & 11.18 & 7.29 & 19.61 & 14.33 & 6.34 & 23.22 \\
\hline & \multicolumn{2}{|l|}{$\operatorname{Ash}(\mathrm{kg})^{\mathrm{e}}$} & 0.0294 & 0.007 & 0.022 & 0.0449 & 0.002 & 0.026 \\
\hline & \multicolumn{2}{|c|}{$\begin{array}{l}\text { Viscosity (Pa-s) @ shear rate } \\
1 \mathrm{~s}^{-1}\end{array}$} & 0.0831 & 0.0027 & 2.251 & 0.1806 & 0.0015 & 17.2 \\
\hline \multirow{6}{*}{$\begin{array}{r}\text { Continuous } \\
\text { disc-stack } \\
\text { centrifuge }\end{array}$} & \multirow[t]{2}{*}{ Wet matter } & Wet mass $(\mathrm{kg})$ & 24.56 & 18.01 & 6.54 & 31.8 & 20.24 & 11.55 \\
\hline & & $\begin{array}{l}\% \text { Of wet mass } \\
\text { in this frac- } \\
\text { tion }\end{array}$ & $\mathrm{Na}$ & 73.33 & 26.6 & $\mathrm{Na}$ & 63.64 & 36.3 \\
\hline & \multirow[t]{3}{*}{ Dry matter } & Dry mass (kg) & 1.99 & 0.92 & 0.83 & 2.76 & 0.97 & 1.77 \\
\hline & & Dry weight- $\%^{\mathrm{b}}$ & 9.45 & 5.08 & 12.64 & 10.33 & 4.81 & 15.31 \\
\hline & & $\begin{array}{l}\% \text { Of dry } \\
\text { mass in this } \\
\text { fraction }^{b}\end{array}$ & $\mathrm{Na}$ & 46.23 & 41.71 & $\mathrm{Na}$ & 46.56 & 64.13 \\
\hline & $\begin{array}{r}\text { Total protein } \% \\
\text { of dry weight }\end{array}$ & Kjeldahl $^{\mathrm{b}}$ & 18.58 & 8.87 & 33.98 & 19.98 & 13.42 & 34.36 \\
\hline
\end{tabular}

One using a lab centrifuge (corresponds to data in Table 2) and one using a continuous disc-stack centrifuge. Data from repeat experiments are in supplementary data

$I D F$ insoluble dietary fibre, SDFP soluble in water, but precipitates in ethanol, SDFS soluble in water, not precipitated in ethanol (oligosaccharides), Total $D F$ total dietary fibre, $G A E$ gallic acid equivalents, $N d$ not determined, $N a$ not applicable

${ }^{a}$ Calculated from centrifugation in duplicate $500 \mathrm{ml}$ batches (values differed from the average by $5<\%$ )

${ }^{\mathrm{b}}$ Values are averages of one sample analysed in duplicate (values differed from the average by $<5 \%$ )

${ }^{c}$ Averages of two samples (values differed from the average by $<6 \%$ )

${ }^{\mathrm{d}}$ Averages of two samples (values differed from the average by $<5 \%$ )

${ }^{\mathrm{e}}$ Averages of two samples, (values differed from the average by $<11 \%$ )

paste from centrifuging the 100 micron filtrate contained one quarter of the wet mass and ca. one-half of the mass from that filtrate. The paste from each filtrate had a total nitrogen content of over $32 \%$ of the dry mass, when measured by Kjeldahl or Dumas methods, and ca. $4-5 \%$ in the supernatant (Table 3). Antioxidant activity as measured by total phenolics was also much higher in the paste than the supernatant or the filtrate. However, DPPH EC50 was much higher (i.e., lower activity) in the paste than in the filtrate (data not shown). All the IDF fibres were found in 
the paste, whilst there was no difference in SDFP or SDFS fibre concentrations in the different fractions. Only small amounts $(<0.3 \mathrm{~g} / \mathrm{L})$ of soluble protein were found in any of the centrifuged fractions. When processed by the discstack centrifuge, a very similar overall picture to that seen with the laboratory centrifuge was seen for the properties measured (Table 3 ). The majority of the dry matter and total nitrogen were recovered in the paste fraction. Furthermore, centrifuging of the filtrate from the 300 micron filter resulted in more solids in the paste fraction than that from the 100 micron filter.

The viscosity of the filtrates and fractions produced by the lab centrifuge were also measured (Table 3 ). The filtrate produced by the 100 micron filter had lower viscosity than that from the 300 micron filter and led to a much lower viscosity in the heavy fraction after centrifugation, than the 300 micron filtrate. Supernatants derived
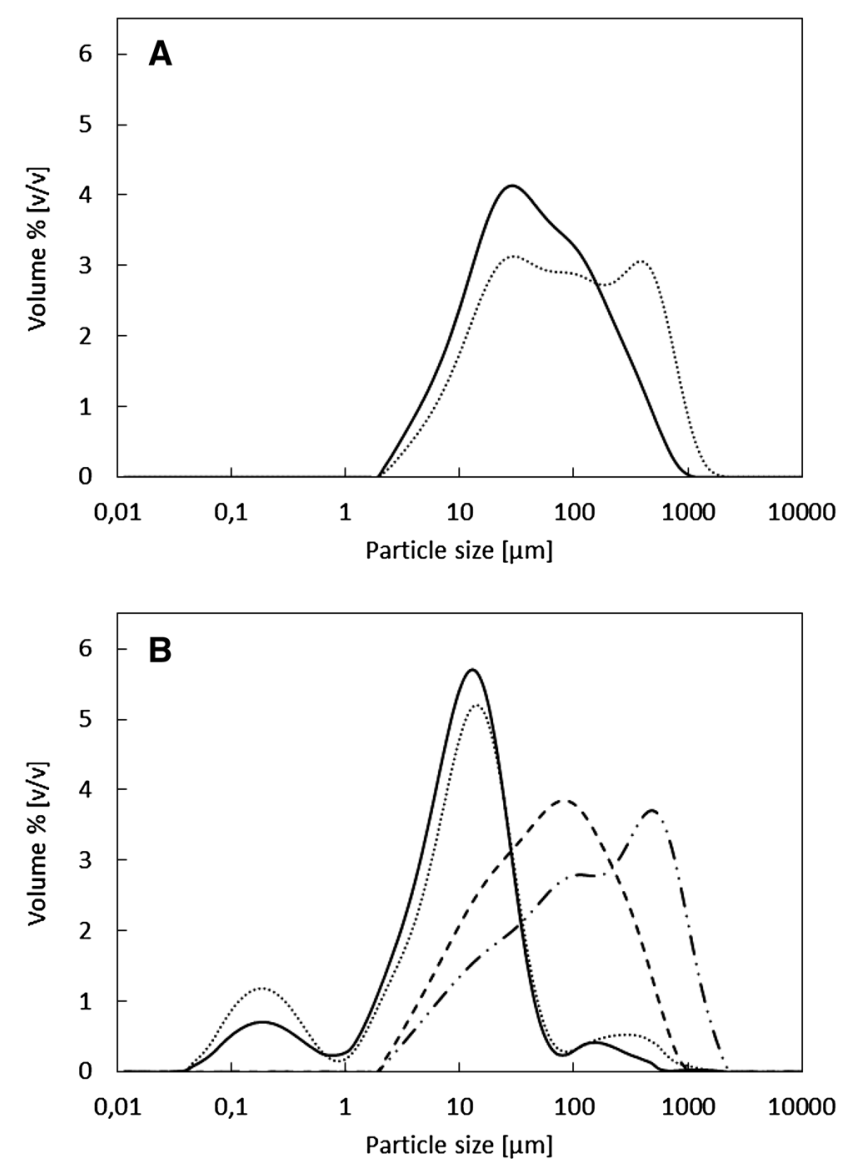

Fig. 5 Particle-size distribution of the filtrate fractions from the rotary drum press and those from the subsequent centrifugation. Two separate sets of BSG were processed: Batch 1 processed with lab centrifuge shown in $\mathbf{A}$ and $\mathbf{B}$; batch 2 processed with disc-stack centrifuge shown in C and D. A Filtrate from 100 micron filter; $\bullet \bullet \bullet$ filtrate from 300 micron. B Lab centrifugation of filtrates from $\mathbf{A}-$ supernatant derived from 100 micron filtrate; - - - paste derived from by centrifugation from both filtrates had viscosity similar to water.

\section{Particle-size distributions in the fractions produced}

The dry matter content in the filtrates from the rotary drum press showed that the 100 micron filter excluded more dry matter than the 300 micron filter (Table 2). It could, thus, be expected that there would also be a difference in the size distribution of particles passing through the 100 micron filter compared to the 300 micron filter. This was tested by analysing filtrates from all four experiments with a Malvern Mastersizer. Similar trends were seen for all of the BSG batches processed, however, only those corresponding to the data in Table 2 will be presented here. The results in Fig. 5 for the filtrate show a difference in the profile of the size distributions from the 100 versus 300 micron filter (Fig. 5B) and suggest a lower average particle size in the former (ca.
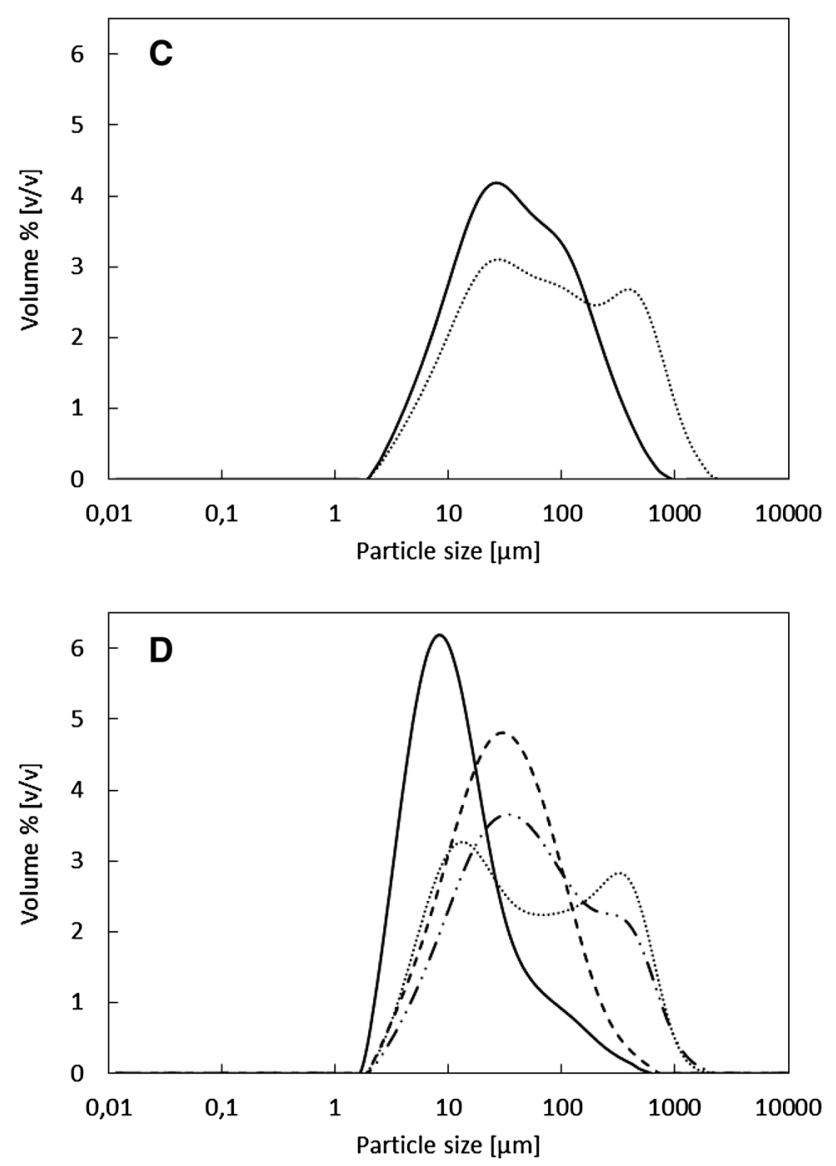

100 micron filtrate; $\bullet \bullet \bullet$ supernatant derived from 300 micron filter;

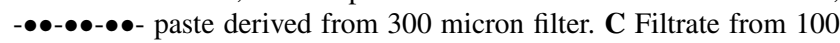
micron filter; $\bullet \bullet \bullet$ filtrate from 300 micron. D Disc-stack centrifugation of filtrates from $\mathbf{C}$-supernatant derived from 100 micron fil-

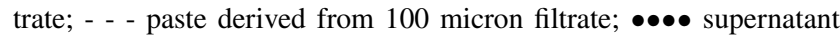

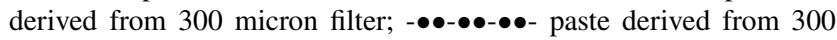
micron filter 
2 micron-900 micron versus 2 micron -1100 micron). Using the software in the particle sizer, an average particle size based on a mode value (i.e., the most frequent particlesize occurrence) gave an average of ca. 30 microns from the 100 micron filter and ca. 363 microns from the 300 micron filter. It is interesting to note that particles much larger than the nominal pore size of the filters were detected. It can be speculated that the particles in solution are not spherical but rather are rod shaped, or that the pressing action of the filter extrudes particles. It can also be speculated that agglomeration between proteins and polyphenols in the filtrate led to formation of particles in the time between undertaking the filtration and analysis, during which time that the samples had been frozen. Cursory observations under a light microscope showed a variety of particle types, but this was not examined further.

Centrifugation of the filtrates shifted the particle-size distributions dramatically. In the supernatants from the 100 or 300 micron filtrates, a Gaussian type distribution with small shoulders (Fig. 5B) and a modal particle size of 13.18 micron were found for both. In contrast, the paste fractions from the 100 micron filtrate shifted to give a close to symmetrical distribution (Fig. 5B) with a modal particle size of 79.43 microns and the paste fraction originating from the 300 micron filtrate had a modal particle size of 478 micron. Similar effects were seen when the continuous disc-stack centrifuge was used (Fig. 5C, D). Here, centrifugation of a 100 micron filtrate with modal particle size of 26.3 micron (Fig. 5C) leads to a supernatant fraction with a modal size of 8.71 micron and a paste fraction with modal size also of 30.2 (Fig. 5D). The filtrate from the 300 micron filter had a double peaked size distribution and two modal sizes of 26.3 and 363 micron (Fig. 5C) which lead to a light and heavy fraction with a similar bi-modal distribution and sizes of 13.18 and 316.2 for the light fraction and 11.48 and 316.2 microns for the heavy fraction after centrifugation (Fig. 5D).

\section{Fractionation of proteins}

The filters used in the rotary drum press cannot be expected to fractionate soluble species; however, given that BSG is a by-product of a hot water extraction during mashing, it can be expected that insoluble and or denatured proteins may remain, which could potentially be fractionated. To analyse for this, the streams from the rotary drum press were extracted using a modified Osborne method to yield three fractions corresponding to albumins/globulins, hordeins, and glutelins, respectively. The protein concentrations were measured with the amido black method. The results showed that there was no significant change in the concentration of these protein groups in filtrate from the rotary drum press compared to the BSG (data in supplementary Table S9). Liquid chromatography-mass spectrometry was also used to determine if there was any difference in the fractions produced by the rotary drum press or centrifugation. When the data were compared with the Uniprot database for barley and extracted from the MaxQuant software, the majority of the barley proteins were present in all liquid fractions and no significant differences could be determined (data not shown).

\section{Fibre}

Fractionation of different fibre types was observed using the rotary drum press (Table 2). In particular, a large upconcentration of fibre in the filter cake was seen, and a subsequent reduction in the filtrate. The 100 micron filter was able to retain more of the fibre than the 300 micron filter (Table 2). Centrifugation of the filtrate led to all of the insoluble fibre segregating to the heavy paste fraction, indicating that it was primarily present as particles (Table 3 ). There was little difference in soluble dietary fibre fractions in the filtrates or filter cake (Table 2), and centrifugation had no fractionating effect upon these (Table 3). The amount of fibre found in BSG and the filter cake (42.35 and 57.35\% on DW basis, respectively) are similar to that reported by the other workers such as Stojceska [24] (53.39\% for BSG) and the differences are most likely due to the different malts and mashing conditions used. The AOAC method 2011.25 separates fibre mainly in terms of solubility and roughly by size (large polysaccharides versus oligosaccharides). A detailed identification of the types of fibres present and their dietary function is extremely complicated and deemed to be outside the scope of the current work. An overall model to describe fibre has been made by the previous workers [25, 26]. Thus, no attempts were made in the current work to further identify the types in the fibre fractions. Nevertheless, based on the use of barley malt in the current work, it can be expected that both soluble and insoluble fibre types would contain arabinoxylan of low or high degrees of polymerisation. Beta-glucan can be expected in the soluble fibre fraction, and this together with arabinoxylan have been shown to contain features that provide health benefits for humans upon consumption [16]. Water-soluble polysaccharides and other types of hemicelluloses and pectin, as well as gums and oligosaccharides can also be expected in the liquid fractions. Water-soluble oligosaccharides can mainly be expected to be fructo-oligosaccharides. Lignin is classified as a noncarbohydrate fibre, but fractions of lignin may be included as dietary fibre by the analytical method used.

\section{Processing of trub}

The precipitate resulting after boiling of the wort is commonly called trub and is known to contain denatured proteins, and is present as a slurry after pumping the wort out to 
the fermenters. Surprisingly, processing of this by-product has received very little attention in the literature. In this study we collected the relatively small amount of trub slurry (ca. $27 \mathrm{~kg}$ ) and processed it with the rotary drum press. The results in Table 2 are shown for one of two separate experiments where similar results were found. It can be seen that most of the liquid passed through the 100 or 300 micron filters, and that a small filter cake fraction could be recovered $(0.6-1.5 \mathrm{~kg})$, which had a greatly increased protein concentration compared with the trub and over tenfold higher than in the filtrate.

\section{Discussion}

The previous reports on the use of brewers spent grains for foods are primarily centred around drying the BSG directly from the brewing process, grinding it, and then incorporating it directly into a food product, see for example Özvural et al. [27] and Stojceskaa et al. [24]. In a few cases, enzyme-aided fractionation has been studied, e.g., by Forssell et al. [28]; however, it is a much longer $(>8 \mathrm{~h})$ and more complicated process than that studied in the current work, which also involves mixing the BSG with warm water before hydrolysis, after which a carbohydrate soluble fraction, protein soluble fraction, and a hydrolysis residue were obtained and freezedried [28]. El-Shafey et al. [8] used a membrane filter press with a woven polypropylene filter cloth, in a small-scale complicated process with many unit operations to dewater BSG for animal feed. The process had a $3 \mathrm{~h}$ cycle time (i.e., it was not a continuous process in contrast to that in the current work), and in it, the BSG was also mixed with water to create a slurry, then filtered, water washed, membrane squeezed, and vacuum dried. The amounts of dried BSG $(2.46 \mathrm{~kg})$ produced were orders of magnitude lower than presented in the current work, but moisture levels were much lower (20-30\%). Recovery, the study nor applications of the liquid streams were considered [8]. In a more recent study, the same workers refined the process and were able to eliminate dilution of the starting BSG and to reduce the moisture levels in the filter cakes to $12-15 \%$ by increasing squeezing pressure and using improved thermal vacuum drying [29]. When a BSG with $25 \%$ solids was squeezed at 60 bar for 3-5 h, 59\% of the water (i.e., ca. 7 L) could be removed [29].

Perhaps, the study closest to what we have reported here is that of Finley et al. [30] from over 40 years ago, in which 45 gallons (ca. $170 \mathrm{~L}$ ) of brewers spent grains were pressed in a type 3A Davenport press. They did not process the trub, nor analyse for fibre, antioxidants, sugars, etc, as was done here. They found that approximately $42 \%$ of the BSG mass was squeezed out as a press water (with 3\% solids), and 58\% ended as a press cake; in the latter, the water content was $70 \%$. Comparison with Table 2 in the current work shows that the rotary drum press used here was able to press more water from the spent grains (50\% of the mass) and yielded a filter cake with higher percentage dry weight (35\% versus $30 \%$ ). In the study of Finley et al. [30], the press water was centrifuged in an International size 2 centrifuge with solids collecting bowl and 5\% of the mass ended as a pellet and $95 \%$ as a clarified press water, which contained $1.6 \%$ solids [30]. The clarified press water was added to beer wort before boiling and could account for $11 \%$ of the total water used in the brew. They concluded that beer produced in this way was indistinguishable from the conventional beer. The sediment from centrifugation was freeze-dried to yield a protein concentrate with $50-55 \%$ protein and when mixed with the other ingredients could be used in an extruder to produce different foods. The solid fraction of spent grains was dried for animal feed [30]. In the current work, the filtrate and filter cake fractions contained ca. $17-20 \%$ of dry matter as protein (Table 2) which increased to $32-34 \%$ of dry matter in the paste after centrifugation (Table 3 ).

Up-concentration of total phenolics (to $150 \mathrm{mg} \mathrm{GAE} / 100$ $\mathrm{gDW}$ ) was seen in the filter cake from the rotary drum press (Table 2) as compared to the BSG (100 mg GAE/100 gDW). Centrifugation of the filtrate led to up-concentration of total phenolics in the paste fraction (from ca. 63 to $114 \mathrm{mg}$ GAE/100 gDW). These concentrations are almost twice as high as Socaci et al. [31] reported (ca. $60 \mathrm{mg} \mathrm{GAE} / 100$ $\mathrm{gDW}$ ) in water-extracted BSG samples, but very similar to what was found with the best extraction mixture of acetone and water (114 mg/100 gDW). Socaci [31] also measured antioxidant activity with DPPH, but reports the values as percentage of radical inhibition rather than as EC50 values which we report. They found the values of $15 \%$ for waterextracted BSG samples, which could be increased to $45 \%$ when acetone-water mixtures were used. The results from the other workers $[28,31,32]$, therefore, suggest that the process which we have examined here could be augmented by BSG pretreatments (such as solvent extraction or enzymatic hydrolysis) yielding even higher values for functional food ingredients and could be considered in a further work. A number of workers have reported that BSG extracts contain metabolites with potentially useful functionalities [31, 32].

The filtrate and filter cake produced by the rotary drum press, and subsequent centrifugation in this work were derived from BSG collected hygienically from a microbrewery running under safe food (HACCP, i.e., hazard analysis and critical control points) principles, using equipment made with food approved contact materials. They, therefore, retain their status as food and can be used as food ingredients. Nevertheless, as with BSG itself [33], the fractions are prone to microbial contamination and must be used in foods immediately, or stabilised to prevent their deterioration. However, more work needs to be conducted to determine the most 
industrially relevant (with respect to costs and functionality of the fractions) means of achieving this. We have shown here that the fractions can potentially provide a source for dietary fibre, antioxidants (polyphenols), protein, and some sugars. Amateur tasting by the authors reveals the fractions to be neutral in flavour, with cereal notes, and very low bitterness. The concentration of the soluble sugars in the liquid streams is influenced greatly by the efficiency of the mashing and lautering process in the brewery which the BSG originates from. After clarification of the filtrates by centrifugation, they could potentially be added to wort for beer making as proposed by Finley [30]; however, given that breweries do not make the same beer every time, it is speculated that unwanted flavour components may need to be removed if the process was to be generic and applicable to every batch of beer. Soluble protein levels in the liquid fractions, however, are too low to make them interesting as the basis for protein containing drinks, and would require up-concentration, for example, by ultrafiltration. A variety of preliminary experiments have been conducted with the fractions produced here together with commercial kitchens, canteens, and event organisations which show wide acceptance of their use in a variety of foods. In particular to replace wholly, or in part, water or flour added during production of foods such as bread, sausages, yoghurt, cakes, and crisp bread. Preliminary results suggest that the fractions can be used to enhance these foods, by altering water retention, mouthfeel, 'crumb', colour, and crispiness [34, 35], and are in good agreement with other authors findings using unfractionated BSG [27, $32,36]$. A comprehensive study to examine the functional effects of their use in foods is outside the scope of the current study and will be presented in a later work.

To conclude, the results presented here demonstrate that $50 \%$ of the mass of brewers spent grains can be continuously pressed out as a liquid filtrate. It is also possible to fractionate specific compounds into the filtrate or filter cake produced. However, soluble species cannot be fractionated given the filter pore sizes of 100 and 300 micron employed here. For concentrating or fractionating soluble protein, we suggest that an ultrafiltration process could be added after the centrifugation step. Some differences in fractionation performance were seen by employing a 100 micron filter versus a 300 micron filter, and the latter allows greater throughput. The process which we have examined here is an easy add-on to any existing brewery, many of which already have disc-stack centrifuges for yeast separation. All that is required is to transfer the BSG in a hygienic way, directly from the lauter tun or mash-filter press into the rotary drum press. Given that the rotary drum press used here has already been scaled-up and trialled at 80 metric $\mathrm{T} / \mathrm{h}$ [for potato pulp processing (G Larsson Starch Technology AB, Sweden, unpublished results)], it seems reasonable that a full-scale BSG processing line could easily be implemented at any micro-, craft-, or full-scale brewery. BSG could be easily processed by a rotary drum press and centrifuge to food ingredients within the ca. $2 \mathrm{~h}$ window that exists between the mashing and lautering process of one brew and that of the next.

Acknowledgements We thank Hening-Holck Larsen and Novozymes foundation for a scholarship til Radhakrishna Shetty. We acknowledge the support of Groen Omstillingsfond project number 2014-98907. We thank Heidi Olander Petersen and Inge Holmberg for excellent technical assistance on Kjeldahl, Dumas, and antioxidant measurements. We thank Per Hägglund for advice on mass spectrometry measurements.

\section{Compliance with ethical standards}

Conflict of interest The authors declare that they have no conflict of interest.

Compliance with ethics requirements This article does not contain any studies with human or animal subjects.

\section{References}

1. Mussatto S (2014) Brewer's spent grain: a valuable feedstockfor industrial applications. J Sci Food Agric 94:1264-1275

2. Kunze W (2004) Technology Brewing and Malting, 3rd edn. VLB, Berlin

3. Mathias TRS, Alexandre VMF, Cammarota MC, de Mello PPM, Sérvulo EFC (2015) Characterization and determination of brewer's solid wastes composition. J Inst Brew 121:400-404

4. Beer statistics (2017) https://www.brewersofeurope.org. Accessed 30 July 2018. ISBN 978-2-9601382-9-0

5. Weber G (2009) Untersuchungen zur Silierung von Biertrebern. Logos Verlag, Berlin

6. Steiner J, Procopio S, Becker T (2015) Brewer's spent grain: source of valueadded polysaccharides for the food industry in reference to the health claims. Eur Food Res Technol 241:303-315

7. Mussatto SI, Dragone G, Roberto IC (2006) Brewers' spent grain: Generation, characteristics and potential applications. J Cereal Sci 43:1-14

8. El-Shafey EI, Gameiro MLF, Correia PFM, de Carvalho JMR (2004) Dewatering of brewer's spent grain using a membrane filter press: a pilot plant study. Sep Sci Technol 39:3237-3261

9. Lu S, Gibb SW (2008) Copper removal from wastewater using spent-grain as biosorbent. Bioresour Technol 99:1509-1517

10. Canedo MS, de Paula FG, da Silva FA, Vendruscolo F (2016) Protein enrichment of brewery spent grain from Rhizopus oligosporus by solid-state fermentation. Bioprocess Biosyst Eng 39:1105-1113

11. Mussatto SI, Roberto IC (2005) Acid hydrolysis and fermentation of brewer's spent grain to produce xylitol. J Sci Food Agric 85:2453-2460

12. Zhuang S, Shetty R, Hansen M, Fromberg A, Hansen PB, Hobley TJ (2017) Brewing with $100 \%$ unmalted grains: barley, wheat, oat and rye. Eur Food Res Technol 243:447-454

13. Celus I, Brijs K, Delcour JA (2006) The effects of malting and mashing on barley protein extractability J. Cereal Sci 44:203-211

14. Osborne TB (1924) The vegetable proteins, 2nd edn. Longmans, Green and Co, London 
15. Kupetz M, Geiinger C, Gastl M, Becker T (2018) Comparison of Dumas and Kjeldahl method for nitrogen determination in malt, wort and beer. Brewing Sci 71:18-23

16. Oehlenschläger J (1997) WEFTA interlaboratory comparison on nitrogen determination by Kjeldahl digestion in fishery products and standard substances. Inf Fischwirtsch Fischereiforsch 44:31-37

17. Jones DB (1941) Factors for converting percentages of nitrogen in foods and feeds into percentages of proteins. Circular 183, US Department of Agriculture Washington, DC

18. Elementar (2017) Dumas - a well-established method for $n /$ protein analysis. Technical Note http://www.elementar.de/en/produ cts/nprotein-analysis/rapid-max-n-exceed.html. Accessed 30 July-2018

19. Popov N, Schmitt M, Schulzeck S, Matthies H (1975) Eine störungsfreie mikromethode zur bestimmung des proteingehaltes in gewebehomogenaten. Acta Biol Med Ger 34:1441-1446

20. Glatter T, Ludwig C, Ahrne E, Aebersold R, Heck A, Schmidt A (2012) Large-scale quantitative assessment of different in-solution protein digestion protocols reveals superior cleavage efficiency of tandem lys-C/trypsin proteolysis over trypsin digestion. J Proteom Res 11:5145-5156

21. Farvin KHS, Jacobsen C (2013) Phenolic compounds and antioxidant activities of selected species of seaweeds from Danish coast. Food Chem 138:1670-1681

22. Farvin KHS, Jacobsen C (2015) Antioxidant activity of seaweed extracts: in vitro assays, evaluation in 5\% fish oil-in-water emulsions and characterization. J Am Oil Chem Soc 92:571-587

23. Farvin KHS, Andersen LL, Nielsen HH, Jacobsen C, Jakobsen G, Johansson I, Jessen F (2014) Antioxidant activity of cod (Gadusmorhua) protein hydrolysates: in vitro assays and evaluation in 5\% fish oil-in-water emulsion. Food Chem 149:326-334

24. Stojceskaa V, Ainswortha P, Plunketta A, Íbanoglu S (2008) The recycling of brewer's processing by-product into ready-to-eat snacks using extrusion technology. J Cereal Sci 47:469-479

25. Westenbrink S, Brunt K, van der Kamp JW (2013) Dietary fibre: challenges in production and use of food composition data. Food Chem 140:562-567

26. Rainakari AI, Rita H, Putkonen T, Pastell H (2016) New dietary fibre content results for cereals in the Nordic countries using AOAC 2011.25 method. J Food Compos Anal 51:1-8
27. Özvural EB, Vural H, Gökbulut I, Özbas Ö (2009) Utilization of brewer's spent grain in the production of frankfurters. Int J Food Sci Technol 44:1093-1099

28. Forssell P, Treimo J, Eijsink VGH, Faulds CB, Collins S, Schols HA, Hinz SWA, Myllymäki O, Tamminen T, Zoldners J, Viljanen K, Waldron KW, Buchert J (2011) Enzyme-aided fractionation of brewer's spent grains in pilot scale. J Am Soc Brew Chem 69:91-99

29. Machado RM, Rodrigues RAD, Henriques CMC, Gameiro MLF, Ismael MRC, Reis MTA, Freire JPB, Carvalho JMR (2016) Dewatering of brewer's spent grain using an integrated membrane filter press with vacuum drying capabilities. Sep Sci Technol 51:692-700

30. Finley JW, Walkera CE, Hautala E (1976) Utilisation of press water from brewer's spent grains. J Sci Food Agric 27:655-660

31. Socaci SA, Farcas AC, Diaconeasa ZM, Vodnar DC, Rusu B, Tofan M (2018) Influence of the extraction solvent on phenolic content, antioxidant, antimicrobial and antimutagenic activities of brewers' spent grain. J Cereal Sci 80:180-187

32. McCarthy AL, O'Callaghan YC, Piggott CO, Fitzgerald RJ, O'Brien NM (2013) Brewers' spent grain; bioactivity of phenolic component, its role in animal nutrition and potential for incorporation in functional foods: a review. Proc Nutrition Soc 72:117-125

33. Robertson JA, I'Anson KJA, Treimo J, Faulds CB, Brocklehurst TF, Eijsink VGH, Waldron KW (2010) Profiling brewers' spent grain for composition and microbial ecology at the site of production. Food Sci Technol 43:890-896

34. Rørby K (2018) Effect on the properties of bread of using fractions from brewers spent grains as an ingredient. Masters thesis, Technical University Denmark, Denmark

35. Jensen M (2018) Funktionelle effekter af separeret mask i pølser. Masters thesis, Technical University Denmark, Denmark

36. Öztürk S, Özboy Ö, Köksel H (2002) Effects of brewer's spent grain on the quality and dietary fibre contrent of cookies. J Inst Brew 108:23-27

Publisher's Note Springer Nature remains neutral with regard to jurisdictional claims in published maps and institutional affiliations. 